\title{
Исследования эндотермического отопления зданий
}

\section{Йонас Юодвалькис,}

Эгидиюс Блажявичюс,

\section{Юрате Карбаускайте}

Институт архитектуры и строительства Каунасского технологического университета, ул. Тунелё 60, LT-44405 Каунас, Литва E-mail:asi@asi.lt
В статье рассматривается весьма актуальная тема энергосбережения в отапливаемых зданиях. Температура наружных поверхностей ограждений выше температуры окружающей среды, и у тепла, покидающего здание, температурный потенциал выше, чем в окружающей среде. Поэтому предлагается оригинальная идея эндотермического отопления - устранение теплопотерь здания путем их возвращения в отапливаемые помещения после регенерации в теплонасосной установке.

В настоящее время источником низкой температуры теплонасосной отопительной системы в основном служит окружающая среда: грунт, вода или воздух. Предлагается использовать рециркуляцию тепла с наружных поверхностей ограждений зданий, устанавливая испарительные элементы теплового насоса в дополнительном слое ограждения с наружной стороны (в оболочке). При поглощении всех теплопотерь здание становится закрытым адиабатным пространством. Тепло циркулирует в пределах здания (эндотермический процесс), при этом используется минимальное количество внешней энергии для работы теплонасосной установки.

Преимущества эндотермической системы отопления: тепловыделение из отапливаемых зданий отсутствует, т. е. исключается тепловое загрязнение окружающей среды соответственно сокращается эмиссия веществ, создающих парниковый эффект, существенно снижается расход энергии на отопление по сравнению с традиционными системами отопления.

В Институте архитектуры и строительства Каунасского технологического университета планируется исследовать эндотермическую систему отопления на экспериментальной модели здания.

Ключевые слова: эндотермическая система отопления, регенерация тепла, тепловой насос, экономия энергии

\section{ВВЕДЕНИЕ}

Тепловая энергия с наружных поверхностей ограждений отапливаемого здания поступает в окружающую среду. Температура наружных поверхностей выше температуры окружающей среды (на 0,3-4 К). Теряемое тепло рассеивается в атмосфере. На тепловизионных снимках отапливаемых зданий видно, что наружные поверхности распространяют инфракрасное излучение в зависимости от конструкции ограждений, поэтому имеется возможность тепловую энергию низкотемпературного источника использовать для теплонасосной системы. С помощью термодинамического цикла холодильной машины целесообразно уловить теряемое зданием тепло и после регенерации возвращать его в отапливаемые поме- щения тех же зданий, т. е. вновь использовать в системе отопления. Задача состоит в том, чтобы заставить тепловую энергию циркулировать в пределах здания. Специальными средствами в ограждениях здания следует создать адиабатные условия, заставить тепловую энергию циркулировать в пределах здания, т. е. обеспечить отсутствие теплопотерь. Теоретические расчеты показали, что для поддержания циркуляции тепла внутри здания внешней энергии требуется в несколько раз меньше, чем в традиционных системах отопления (в зависимости от коэффициента преобразования энергии теплового насоса - СОР). При этом следует отметить, что в случае полной утилизации теплопотерь в процессе регенерации тепла образуется избыточное количество тепловой энергии, равное количеству энергии, поступающей в здание 
извне. Здание становится источником энергии, которая может быть использована в пределах этого здания или передана внешним потребителям. Исследования такой схемы использования энергии предусмотрены и в международной программе COST C23.

\section{ТЕОРЕТИЧЕСКИЕ ОСНОВЫ}

В предлагаемой системе отопления тепловая энергия циркулирует внутри здания. Такую систему отопления следует называть эндотермической, потому что теплопотери здания отсутствуют.

Предварительные расчеты и, частично, экспериментальные исследования показывают, что технически создание и оборудование такой (эндотермической) системы отопления имеет практическую перспективу.

Поскольку в Литве планируется использовать атомную энергию, внедрение эндотермических систем отопления (адиабатных зданий) вполне реально.

Частичная регенерация тепла с помощью тепловых насосов довольно широко используется в настоящее время в современных зданиях производственного назначения и в помещениях с вытяжной вентиляцией, в которых большие теплопотери связаны с удалением воздуха из отапливаемых помещений. Однако существуют технические возможности сбора и возвращения теплопотерь здания и с наружных поверхностей ограждающих конструкций (стен, окон, полов, перекрытий).

На рис. 1 изображен фрагмент наружного ограждения здания. Для создания адиабатных условий, т. е. удержания теплового потока в ограждении, оборудован дополнительный слой 3 в основной стенке 1 с воздушной прослойкой 2, в которой установлен испаритель (абсорбер) 4 теплового насоса. Работа испарителя 4 отрегулирована в таком режиме, при котором температура воздушной прослойки 2 была бы не выше температуры окружающей среды $\theta_{e}$.

При таком режиме температуры поверхностей дополнительного слоя:

$$
\theta_{3} \leq \theta_{4}
$$

Это означает, что теплопотери через дополнительный слой 3 отсутствуют, ограждение приводится к адиабатным условиям. При устройстве дополнительного слоя ограждения теплопотери уменьшаются и без испарительного элемента 4. Однако тепловой поток $q_{2}$ через ограждение

$$
q_{2}>0
$$

При отсутствии дополнительного слоя тепловой поток через ограждение будет:

$$
q_{1}=U_{1}\left(\theta_{i}-\theta_{e}\right)
$$

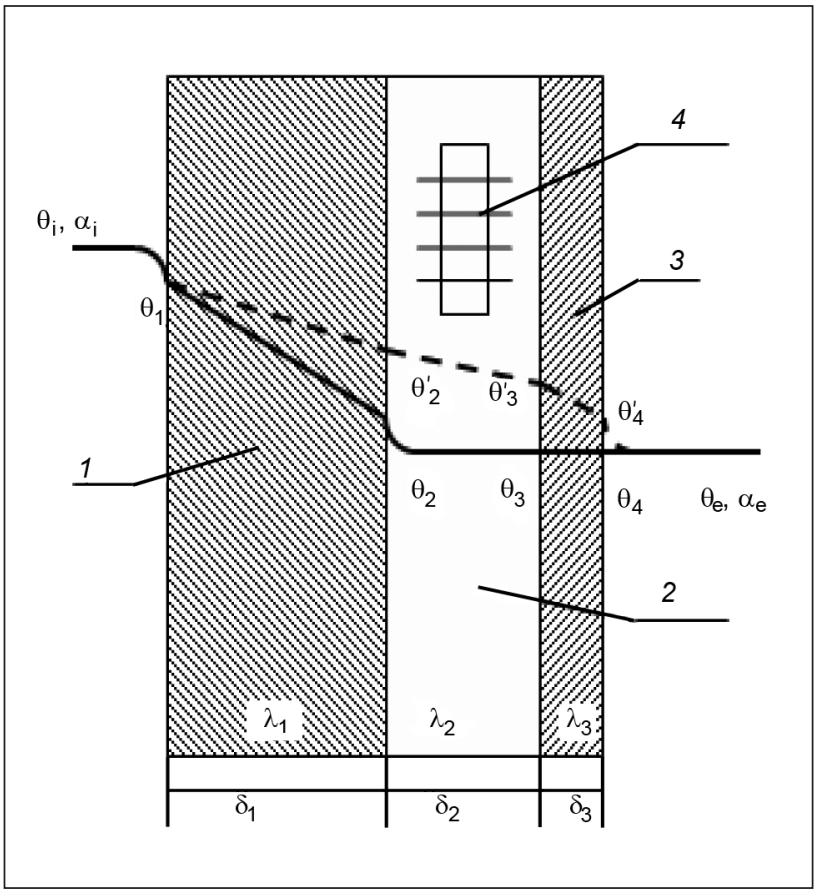

Рис. 1. Распределение температуры поверхностей слоев стены при стационарном режиме теплопередачи через ограждения - температурная диаграмма при установке абсорберов

---- температурная диаграмма без абсорберов

1 - основной слой ограждения; 2 - воздушная прослойка; 3 - дополнительный слой ограждения (оболочка); 4 - испаритель (абсорбер);

$\theta_{\mathrm{i}}$ - расчетная температура помещения; $\theta_{\mathrm{e}}$ - расчетная температура наружного воздуха; $\theta_{1^{\prime}} \theta_{2^{\prime}} \theta_{3^{\prime}} \theta_{4^{\prime}} \theta_{2^{\prime}}^{\prime} \theta_{3^{\prime}}^{\prime} \theta_{4}^{\prime}-$ температуры поверхностей слоев при соответствующем режиме теплопередачи; $\alpha_{i^{\prime}} \alpha_{e}-$ соответствующие коэффициенты теплоотдачи; $\lambda_{1^{\prime}} \lambda_{2^{\prime}} \lambda_{3}-$ коэффициенты теплопроводности соответствующих слоев; $\delta_{1^{\prime}} \delta_{2^{\prime}} \delta_{3}-$ толщина слоев

где $U_{1}=\frac{1}{\frac{1}{\alpha_{i}}+\frac{\delta_{i}}{\lambda_{1}}+\frac{1}{\alpha_{e}}}$.

С дополнительным слоем 3 тепловой поток через ограждение:

$$
q_{2}=U_{2}\left(\theta_{i}-\theta_{e}\right)
$$

$$
\text { где } U_{2}=\frac{1}{\frac{1}{\alpha_{i}}+\frac{\delta_{i}}{\lambda_{1}}+\frac{\delta_{2}}{\lambda_{2}}+\frac{\delta_{3}}{\lambda_{3}}+\frac{1}{\alpha_{e}}} \text {. }
$$

Естественно, $U_{1}>U_{2}$ и $q_{2}<q_{1}, q_{2}>0$. С увеличением теплового сопротивления ограждения теплопотери снижаются, однако их нулевое значение $q_{2}$ экономически нецелесообразно.

При поддержании режима $\theta_{3} \leq \theta_{4}$ весь тепловой поток через ограждение 1 поглощается элементами испарителя 4 и внутри помещения через конденсатор холодильной машины (теплового насоса) выделяется энергия (тепло) $[4,5]$ в количестве:

$$
Q_{n}=Q_{\text {пот }}+A L=\varepsilon A L,
$$


где $Q_{n}$ - количество тепла, отдаваемое конденсатором теплового насоса;

$Q_{\text {пот }}$ - теплопотери через наружные ограждения;

$A L$ - энергия от внешнего источника, потребляемая компрессором;

$\varepsilon-$ коэффициент преобразования энергии (СОР).

$$
\frac{Q_{\text {пот }}}{A L}=\varepsilon-1
$$

Экономически целесообразно оборудование адиабатного ограждения, когда:

$\varepsilon-1>1$, т. е. при $\varepsilon>2$.
Если удается полностью уловить теплопотери здания, внутри здания создается избыточное количество энергии, которое можно использовать для других нужд в том же здании или реализовать за его пределами.

Для сравнения на рис. 2 изображена диаграмма потоков энергии в здании с различными системами отопления.

В отличие от I-го и II-го вариантов в III-ем варианте теплопотери в окружающую среду отсутствуют. Избыточное тепло в этом варианте равно использованной энергии в компрессорной установке.

Для сравнения ориентировочные данные расхода энергии в зданиях с различными системами отопления, изображенными на рис. 2, представлены в таблице.

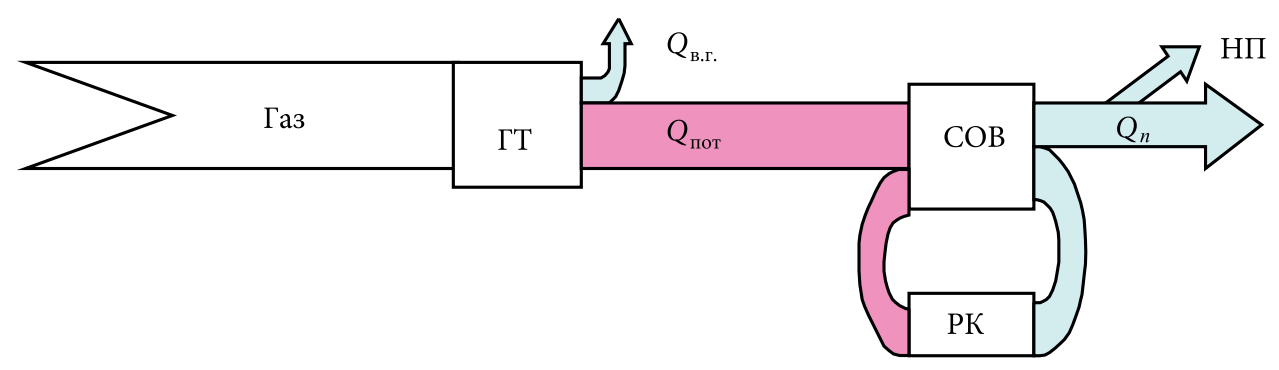

Вариант I. Традиционная система отопления

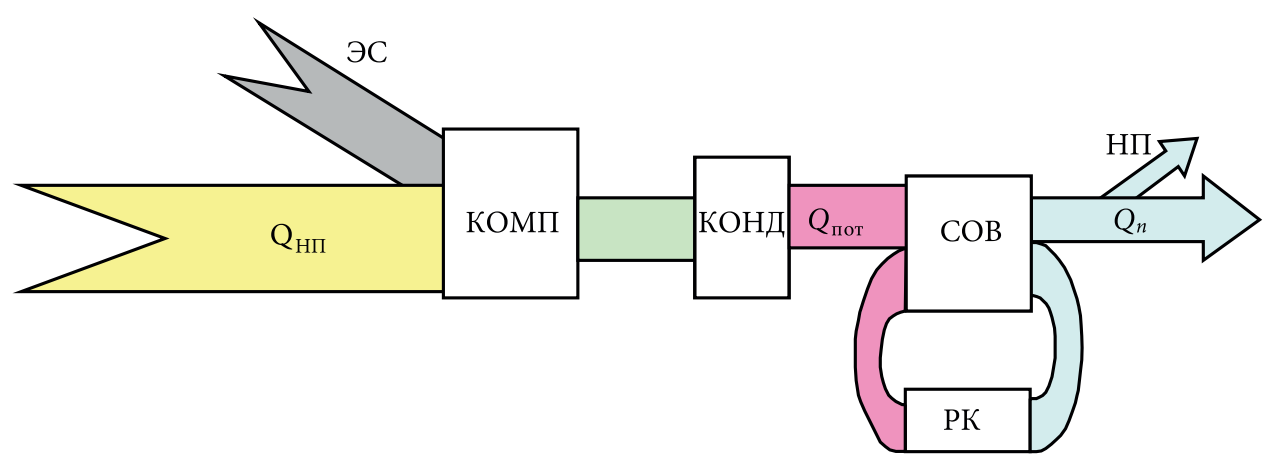

Вариант II. Геотермическая система отопления

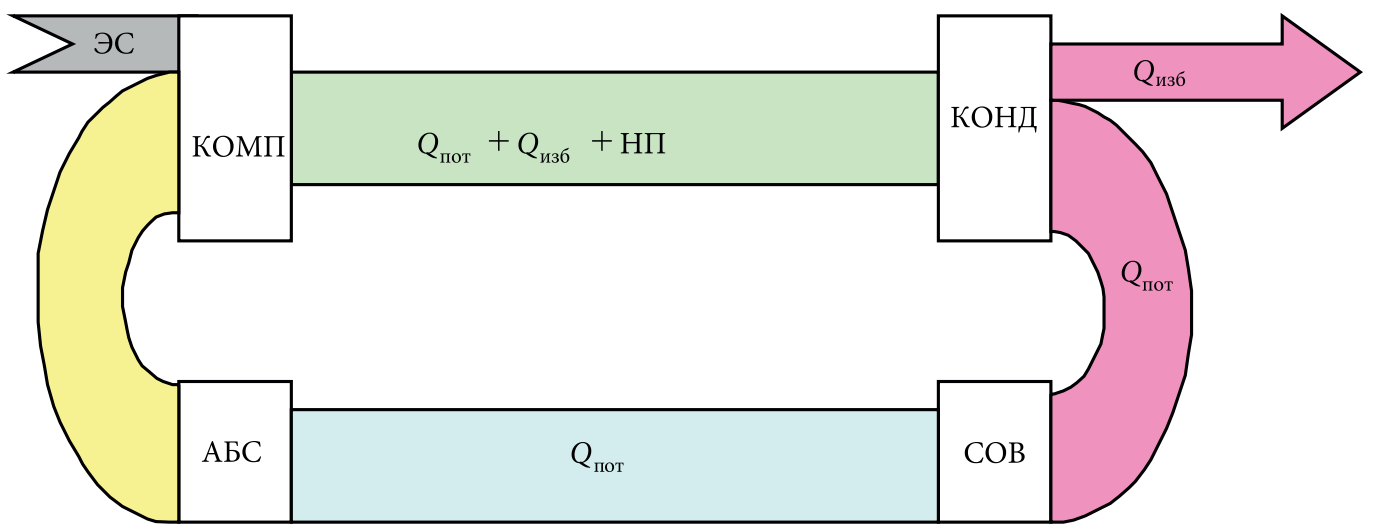

Вариант III. Эндотермическая система отопления

Рис. 2. Сравнительные потоки энергии при различных системах отопления зданий. ГТ - генератор тепла; СОВ - система отопления и вентиляции; КОМП - компрессор; КОНД - конденсатор; АБС - испаритель (абсорбер); ЭС - электросеть; PK - рекуператор; $Q_{\text {пот }}$ - теплопотери здания; $Q_{n}-$ потери тепла в окружающую среду; $H$ П - неучтенные потери тепла; $Q_{\text {изб }}-$ избыточная энергия; $Q_{\text {нп }}-$ источник энергии низкого потенциала; $Q_{\text {в.г. }}-$ потери тепла с дымовыми газами 
Табл ица. Расход энергии в зданиях с различными системами отопления

\begin{tabular}{|c|c|c|c|c|c|c|c|}
\hline Тип системы отопления & $\begin{array}{c}\text { Расчетные } \\
\text { теплопотери } \\
\text { здания, } Q_{\text {по' }} \\
\text { кВт } \\
\end{array}$ & $\begin{array}{c}\text { Мощность } \\
\text { энергетиче- } \\
\text { ского потока } \\
\text { извне, } Q_{p}, k B т \\
\end{array}$ & \begin{tabular}{|c|} 
Мощность теплового \\
потока утилизиро- \\
ванных теплопотерь, \\
$\mathbf{Q}_{\text {yr }}$ кBт \\
\end{tabular} & $\begin{array}{c}\text { Мощность } \\
\text { производимой в } \\
\text { здании энергии, } \\
\mathbf{Q}_{\text {в.п. }} \text {, кВт } \\
\end{array}$ & \begin{tabular}{|c|} 
Коэффициент \\
преобразования \\
энергии здания $\varepsilon$
\end{tabular} & $\begin{array}{c}\text { Tеплопотери } \\
\text { здания, } \\
\mathbf{Q}_{\text {вн.с.' }}, \mathbf{K B T}\end{array}$ & $\begin{array}{c}\text { Избыток } \\
\text { энергии, } \\
Q_{\text {изб }}, \text { кВт }\end{array}$ \\
\hline $\begin{array}{l}\text { 1. Традиционная } \\
\text { система отопления, } \\
\text { природный газ }\end{array}$ & 10,0 & 11,11 & - & 10,0 & 0,9 & 10,0 & $-1,11$ \\
\hline $\begin{array}{l}\text { 2. Традиционная } \\
\text { система отопления, } \\
\text { электроэнергия }\end{array}$ & 10,0 & 10,0 & - & 10,0 & 1,0 & 10,0 & - \\
\hline $\begin{array}{l}\text { 3. Геотермическая } \\
\text { система отопления, } \\
\text { привод компрессора } \\
\text { от электродвигателя }\end{array}$ & 10,0 & 3,33 & - & 10,0 & 3,0 & 10,0 & - \\
\hline $\begin{array}{l}\text { 4. Эндотермическая } \\
\text { система отопления }\end{array}$ & 10,0 & 5,0 & 10,0 & 15,0 & 3,0 & - & 5,0 \\
\hline
\end{tabular}

Одной из простейших систем эндотермического отопления зданий с минимальными потерями тепла является система воздушного отопления. На рис. 3 показана упрощенная эндотермическая схема такой системы. Предлагаемая система довольно простая, и ее легко оборудовать. Предусматривается устройство двух закрытых контуров: низкого и высокого потенциала для передачи тепла в помещения. В воздушной прослойке в наружных ограждениях с помощью абсорберов АБС уловленное тепло в виде паров рабочего агента передается в тепловой насос ТН. Конденсат рабочего агента из теплонасоса возвращается в испаритель АБС. Также используется

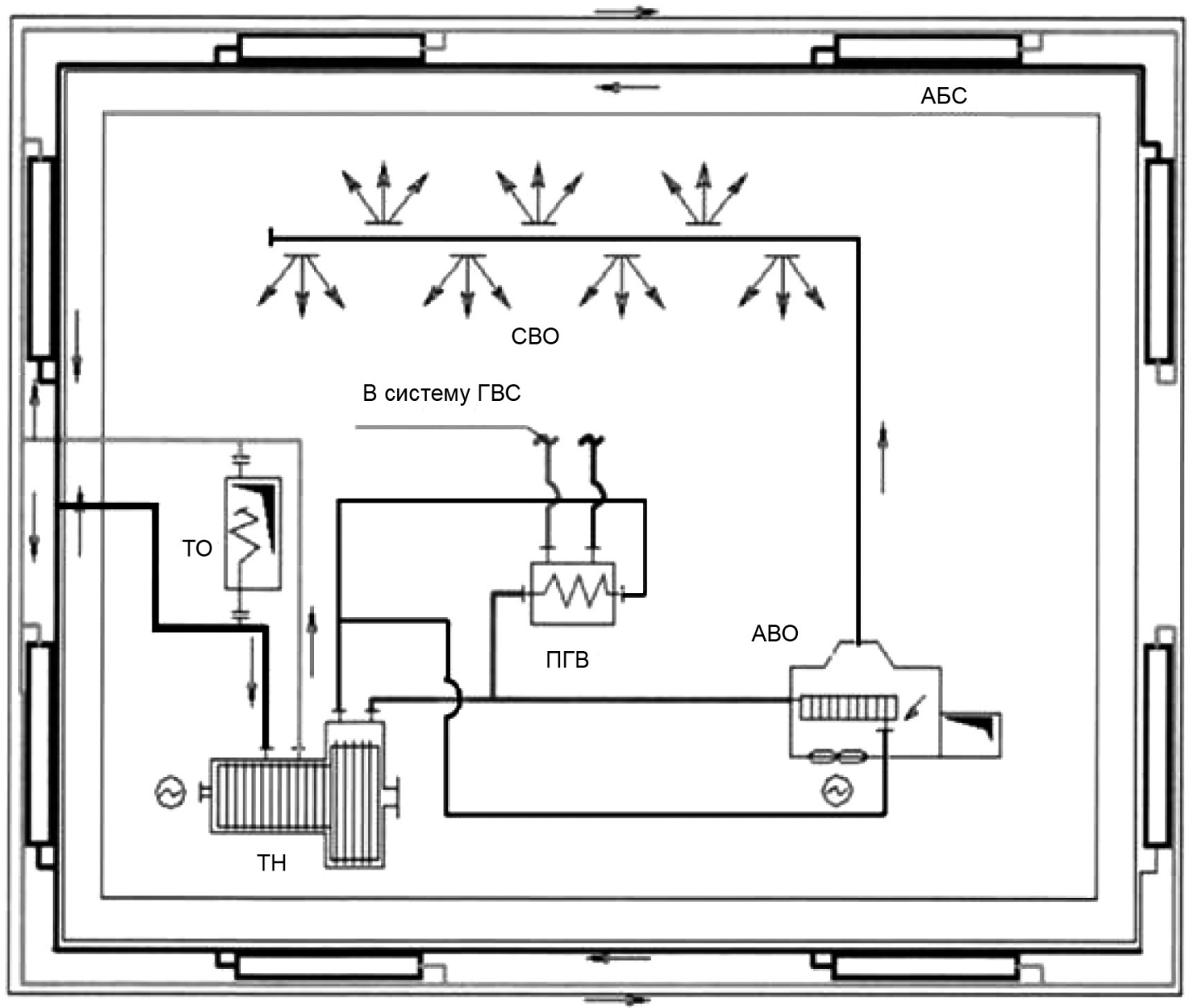

Рис. 3. Схема адиабатного здания с системой воздушного отопления: ТН - тепловой насос; Т0 - теплообменник; АВО - агрегат воздушного отопления; ПГВ - подогреватель горячего водоснабжения; СВО - система воздушного отопления; АБС - абсорбер, ГВС - система горячего водоснабжения 
тепло удаляемого из помещений воздуха путем устройства теплообменника в вытяжной шахте. При такой системе тепло циркулирует в пределах здания, т. е. исключается потребность в наружном источнике низкого потенциала.

В Институте архитектуры и строительства Каунасского технологического университета планируется начать работы по устройству макета здания для проверки идеи возможности оборудовать эндотермическую систему отопления.

\section{ТЕХНИЧЕСКАЯ ВОЗМОЖНОСТЬ ОБОРУДОВАНИЯ ЗДАНИЯ ЭНДОТЕРМИ- ЧЕСКОЙ СИСТЕМОЙ ОТОПЛЕНИЯ}

Техническое оборудование эндотермической системы отопления зданий в принципе не отличается от широко применяемых на практике в настоящее время систем отопления с теплонасосными установками. Отличие заключается в том, что коллекторы поглощения тепла низкотемпературного потенциала располагаются не в наружных источниках тепла, а в пределах того же здания - в наружном слое ограждения. Таким образом, поглощенное от наружных ограждений тепло после регенерации возвращается в отапливаемые помещения. Особенно важно отметить, что тепло из ограждений здания не выделяется в окружающую среду. По сравнению с I-ым вариантом (рис. 2) при эндотермической системе отопления отсутствуют выбросы тепла, т. е. и тепловое загрязнение окружающей среды.

Возникают сомнения относительно стоимости оборудования эндотермических систем отопления. Трудно сравнивать стоимость геотермической системы отопления с эндотермической, поскольку эндотермических систем в настоящее время пока нет. Однако для геотермических систем отопления „земля-воздух“ основных затрат требует оборудование подземных коллекторов тепла. Для поглощения низкотемпературного тепла требуется площадь участка 30-125 м²/кВт, а для теплонасосной установки „воздух-воздух“ 4-10 м²/кВт поверхности теплообменника. Для обеспечения адиабатного ограждения также требуется предполагаемая поверхность теплообменника порядка 5-15 м²/кВт. Поверхности теплообменника должны быть установлены во время строительства здания. Ограждения такого здания, видимо, должны отличаться от традиционных, применяемых в обычных зданиях. Следует отметить, что кроме компрессорных вариантов устройства эндотермических систем отопления, возможны варианты с абсорбционными, термоэлектрическими и другими системами охлаждения.

\section{ВЫВОДЫ}

1. Предлагается оригинальная идея эндотермической системы отопления здания, практически исключающей теплопотери здания.

2. При внедрении эндотермической системы отопления зданий существенно снижаются тепловое загрязнение и парниковая эмиссия в окружающую среду, расход энергии на отопление здания снижается не менее чем вдвое по сравнению с традиционными системами отопления.

3. Здание становится источником энергии, направленной на удовлетворение потребностей в энергии внутри здания или предназначенной для внешних потребителей.

4. Для продолжения работ по созданию зданий с эндотермической системой отопления необходимы экспериментальные исследования моделей здания в лабораторных условиях. Задача следующего этапа - спроектировать и построить экспериментальные дома с такой системой отопления.

Поступило 20012011

Принято 25032011

\section{Литература}

1. Juodvalkis J. Nestacionarieji šilumos mainai pastatuose. Kaunas: Technologija, 2008. 203 p.

2. Aleksandravičius T. A., Klementavičius A., Krakauskas M. Šilumos siurbliu panaudojimo galimybés Lietuvoje. Lietuvos energetikos ministerijos VIt „Energetikos agentūros energijos taupymo direkcija“, 1996. 40 p.

3. Бамбущек Е. М. и др. Тепловые и конструктивные расчеты холодильных машин. Ленинград, 1987. 423 с.

4. Gimbutis G. S., Klimas L. N., Dagilis V. Šilumos transformacijos pagrindai. Kaunas: Technologija, 1993. 146 p.

5. Reay D., MacMichael D. Heat Pumps. Design and Applications. Oxford, 1979. 302 p.

Jonas Juodvalkis, Egidijus Blaževičius, Jūratė Karbauskaitė

\section{ENDOTERMINIO PASTATU ŠILDYMO TYRIMAI}

Santrauka

Nagrinėjamos šildomų pastatų energijos taupymo galimybès. Per pastato išorines atitvaras perduodamos šilumos temperatūros potencialas yra aukštesnis, palyginus su aplinkos oro temperatūra. Todèl siūloma originali endoterminio šildymo idejja - išvengti pastatų šilumos nuostolių, sugrąžinant ją i šildomas patalpas po regeneracijos šilumos siurblyje. Dabar pastatų šildymo sistemose ịrengiamų šilumos siurblių žemos temperatūros šaltiniu dažniausiai yra aplinkos oras arba gruntas. Siūloma panaudoti per pastato išorines atitvaras prarandamą šilumą, pastato atitvarose įrengiant šilumos siurblio garintuvus. Ribiniu atveju, panaudojant visą pastato prarandamą šilumą, jis tampa uždara adiabatine erdve. Šiluma cirkuliuoja pastate (endoterminis procesas), panaudojant 
išorinę energiją sistemos siurblio darbui. Esant tokiai šildymo sistemai, namo šilumos nuostoliai praktiškai eliminuojami.

Nagrinejjamos endoterminès šildymo sistemos pranašumai: nelieka šildomų pastatų išskiriamos ị aplinką šilumos, sumažeja aplinkos šiluminè tarša, šiltnamio efektą sukeliančių medžiagų emisija, energijos sąnaudos, palyginus su tradicine šildymo sistema.

Kauno technologijos universiteto Architektūros ir statybos institute numatoma tirti eksperimentinio pastato modelio endotermines šildymo sistemas.

Raktažodžiai: endotermine šildymo sistema, šilumos regeneracija, šilumos siurblys, pastatų šilumos nuostoliai

\section{Jonas Juodvalkis, Egidijus Blaževičius, Jūratė Karbauskaitė \\ INVESTIGATION OF ENDOTHERMIC BUILDING HEATING SYSTEM}

Sum mary

The energy retention problems of heated buildings are treated in the paper. The potential of heat transferred through the building envelope is higher in comparison with the environmental potential at outdoor temperature. Therefore, the idea of endothermic heating with a possibility to avoid heat losses by heat recovery into premises after regeneration in the heat pump is proposed. At present, the ground of outdoor air is used as a source of low potential energy in heat pumps of engineering systems in buildings. Authors have suggested to apply the heat transferred through the building envelope as an energy source in absorbers located in the structure of the building envelope. If all heat losses are recovered, the building will become an adiabatic space. In this case, heat will circulate within the building, generating an endothermic process with some external energy needed for heat pump action. Heat losses in such a building would be almost eliminated at the operation of the proposed heating system.

The advantages of the proposed heating system: heat losses of buildings into the environment are eliminated, thermal environmental pollution and greenhouse gas emission are significantly reduced, energy consumption in a building is decreased, especially in comparison with traditional heating systems. An investigation of the experimental model of a building with the endothermic heating system is foreseen at the Institute of Architecture and Construction of the Kaunas University of Technology.

Key words: endothermic heating system, heat recovery, heat pump, building heat losses 